\title{
Progress in severe plastic deformation of metastable beta Ti alloys
}

\author{
Ahmad Zafari, Kenong Xia* \\ Department of Mechanical Engineering, The University of Melbourne, Victoria 3010, Australia \\ ef 1 \\ * Email: k.xia@unimelb.edu.au.
}

Keywords: Severe plastic deformation, $\beta$ titanium alloys, grain refinement, stress induced phase transformation.

\section{Abstract}

Metastable $\beta$ Ti alloys can undergo martensitic transformation under stress. It is shown that such stress induced martensitic transformation (SIMT) can significantly facilitate grain refinement by severe plastic deformation (SPD), achieving $\beta$ grain sizes of $<50 \mathrm{~nm}$, compared to $>100 \mathrm{~nm}$ in $\beta$ Ti alloys without SIMT. The martensitic $\alpha^{\prime \prime}$ formed partitions the $\beta$ grains and blocks dislocation movement, but undergoes reverse transformation back into $\beta$ at large strains, leaving a pure $\beta$ grain structure. The grain refinement can be further enhanced with increasing the strain rate to the order of $10-100 \mathrm{~s}^{-1}$, leading to $\beta$ grains of $<10 \mathrm{~nm}$. SPD also has significant effect on the morphology of the $\alpha$ precipitates upon ageing, transforming it from acicular to equiaxed. Although the $\alpha$ nucleus formed between recrystallised $\beta$ grains of $<\sim 10 \mathrm{~nm}$ follows the Burgers orientation relationship (BOR), the semi-coherent interface is lost upon $\beta$ grain growth during ageing, causing its growth into equiaxed shape.

This is the author manuscript accepted for publication and has undergone full peer review but has not been through the copyediting, typesetting, pagination and proofreading process, which may lead to differences between this version and the Version of Record. Please cite this article as doi: $\underline{10.1002 / a d e m .201900471}$ 


\section{Introduction}

Ultrafine/nano grained (UFG/NG) materials have drawn much attention during the last few decades thanks to their superior mechanical properties including high strength and superplasticity, and unique chemical and physical attributes ${ }^{[1-8]}$. In general, they are produced using either the bottom-up or the top-down approach. The former refers to building the UFG/NG structures by assembly of atoms or nano particles/layers, while the latter to refining originally coarse grains down to $<1 \mu \mathrm{m}$ (UFG) or $<100 \mathrm{~nm}(\mathrm{NG})$. Among the various top-down methods, severe plastic deformation (SPD) is widely used to refine grains in metals during which the microstructure evolves from dislocation cells to subgrains with low angle boundaries to grains with high angle boundaries with increasing strain in simple, single-phase alloys.

The effects of SPD on microstructure, however, become more complicated when phase transformations are involved, as in the case of Ti alloys. There are three main classes of Ti alloys, namely $\alpha, \alpha / \beta$ and $\beta$, with the first two dominated by hep-structured $\alpha$ and the latter by bccstructured $\beta^{[9]}$. Most research on SPD of Ti is focused on the $\alpha$ and $\alpha / \beta$ alloys ${ }^{[10-15]}$ which behave similarly to other alloys. Here we focus on the metastable $\beta$ alloys which are unique in that martensitic transformation can be induced by plastic deformation which would interact with the grain refinement process (unlike in $\alpha$ and $\alpha / \beta$ alloys, no martensitic transformation occurs upon quenching from the $\beta$ phase field $\left.{ }^{[16]}\right)$. In fact, much finer $\beta$ grains of $<50 \mathrm{~nm}$ have been achieved in a metastable $\beta$ alloy with a relatively low $\beta$ stability, thanks to stress induced martensitic transformation (SIMT), compared to $>100 \mathrm{~nm}$ in a more stable alloy without SIMT $^{[17-19]}$. In addition, a very recent study ${ }^{[20]}$ conducted by the authors has revealed that grains as small as $5-10$ $\mathrm{nm}$ are achievable when severe strains are combined with high strain rates whose effects on grain refinement have been largely ignored.

Besides grain refinement, SPD would have significant effects on $\alpha$ precipitation which can be obtained by subsequent aging ${ }^{[9,16]}$. Instead of the usual acicular shape, equiaxed $\alpha$ is formed in This article is protected by copyright. All rights reserved 
severely deformed $\beta$ alloys, leading to an ultrafine $\alpha / \beta$ duplex structure ${ }^{[21-24]}$ with better mechanical properties $^{[25]}$.

In the following sections, we overview the progress and fundamentals in SPD of metastable $\beta$ Ti alloys, focusing on the role played by SIMT in grain refinement, the $\alpha^{\prime \prime}$ to $\beta$ reverse transformation triggered by SPD, the effects of strain rates, and the influence of SPD on $\alpha$ precipitation.

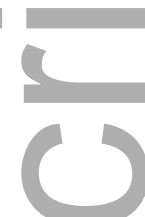

\section{The role of SIMT in grain refinement}

Metastable $\beta$ Ti alloys can generally be classified as lean and rich ${ }^{[16]}$, with the former experiencing SIMT due to lower $\beta$ stability, and the latter without SIMT owing to much higher content of $\beta$ stabilising elements ${ }^{[9]}$. The SIMT produces orthorhombic martensitic $\alpha^{\prime \prime}$ from the parent phase of bcc- $\beta^{[9]}$ and significantly influences mechanical properties, including the doubleyielding phenomenon caused by the formation of $\alpha^{\prime \prime}$ at lower stresses than those required by slip in $\beta^{[26]}$, the shape memory effect due to $\alpha^{\prime \prime}$ to $\beta$ reverse transformation upon unloading ${ }^{[27,28]}$, and enhanced work hardening rate contributing to better ductility as a result of increased resistance to dislocation movement ${ }^{[29-31]}$.

Additionally, SIMT plays a significant role in grain refinement during SPD, although the mechanism for the substantial grain refinement in the metastable alloys has not been addressed by most previous studies. Figure $\mathbf{1}$ shows the grain sizes achieved in a variety of alloys after SPD at room temperature (RT), except for $\mathrm{W}$ processed at $290-330{ }^{\circ} \mathrm{C}<\sim 0.2 \mathrm{~T}_{\mathrm{m}}{ }^{[32]}$, to different equivalent strains. All the materials are either high purity metals ( $99.99 \%)$ or single-phase alloys before SPD. However, the Ti alloys including Ti-5Al-5V-5Mo-3Cr (wt.\%) or Ti-5553, Ti-24.6Nb5Zr-3Sn (at.\%) or TNZ3S, Ti-29Nb-13Ta-4.6Zr (wt.\%) or TNTZ, Ti-36Nb-2.2Ta-3.7Zr-0.3O 
(wt.\%) or TNTZO, and Ti-24Nb-4Zr-7.9Sn (wt.\%) or TNZ7.9S would undergo SIMT to form martensitic $\alpha^{\prime \prime}$ during SPD. It should be noted that large strains will ultimately change $\alpha^{\prime \prime}$ back to $\beta$ ${ }^{[17,19]}$, to be discussed in the next section. Further, although purity of metals ${ }^{[33,34]}$ and SPD at > 0.3-0.4 $\mathrm{T}_{\mathrm{m}}$ would influence grain sizes ${ }^{[35,36]}$, these two factors are not applicable in Figure 1 since the metals are highly pure and processing temperatures are low (i.e. RT or $<0.2 \mathrm{~T}_{\mathrm{m}}$ ). It is apparent that the smallest grain sizes obtained in single phase alloys are generally larger than $100 \mathrm{~nm}$, while the grain sizes in the Ti alloys experiencing SIMT can reach $<50 \mathrm{~nm}$, more than two times finer than the grain size of the single $\beta$ phase Ti-20Mo and Ti-45Nb alloys, indicating that SIMT significantly affects the grain refinement in $\beta$ Ti alloys.

The role played by $\alpha^{\prime \prime}$ in grain refinement is illustrated in Figure 2. A dislocation is generated at a boundary (solid red in Figure 2a) and travels across the grain to reach the opposite side (hollow red) where it decomposes into two other dislocations (blue) and is absorbed into the boundary ${ }^{[3]}$. At the early stages of deformation the rate of dislocation generation is higher than that of the absorption, giving rise to an increase in dislocation density, the formation of subgrains, and eventually, finer grains with high angle boundaries ${ }^{[2]}$. This process continues until the two rates become equal, leading to a steady state with no further grain refinement ${ }^{[39,52]}$. The grain size at the steady state $\left(d_{S}\right)$ can be estimated using ${ }^{[53]}$

$d_{S} \approx \frac{K G b}{\tau}$

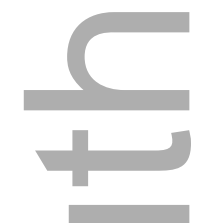

where $K$ is a constant normally taken as $10, G$ the shear modulus, $b$ Burgers vector and $\tau$ the shear stress with the maximum theoretical value of $G / 30^{[54]}$. For Ti-5553, $b$ is calculated to be 0.285 $\mathrm{nm}^{[20]}$, resulting in $d_{S}$ of $\sim 85 \mathrm{~nm}$, close to $d_{S}$ of $\sim 100 \mathrm{~nm}$ for Ti-20Mo and Ti-45Nb but coarser than $<50 \mathrm{~nm}$ observed in the SMIT-involving alloys. Upon being induced by stress, $\alpha "$ can act as an obstacle to dislocation movement, resulting in dislocation pileup in front and preventing dislocations from reaching the boundary to be absorbed (Figure 2b). Consequently, the equilibrium This article is protected by copyright. All rights reserved 
between the rates of dislocation generation and absorption is disrupted ${ }^{[17]}$, leading to the formation of finer (sub)grains thanks to increased dislocation density (Figure 2c). Additionally, any secondary $\alpha "$ formed can pin grain boundaries and limit strain-induced coarsening. Studies on Al alloys ${ }^{\text {[55-57] }}$ have confirmed that nano-sized precipitates significantly enhance grain refinement by increasing the rate of dislocation multiplication and retarding grain boundary migration. Such compartmenting of grains by multiple generations of $\alpha "$ is very effective in refining grains ${ }^{[17]}$.

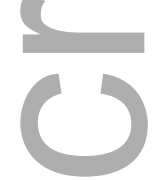

\section{3. $\alpha$ " to $\beta$ reverse transformation at large strains}

It has been shown that the $\alpha^{\prime \prime}$ formed at early stages of straining disappears when sufficient strain is applied, suggesting an $\alpha^{\prime \prime}$ to $\beta$ reverse transformation ${ }^{[17,19,51]}$. The dissolution of a secondary phase after SPD has also been reported in other alloys, including the decomposition of cementite in a pearlitic steel during wire drawing ${ }^{[58]}$ and dissolution of $\theta^{\prime}$ in $\mathrm{Al}-1.7$ at.\% $\mathrm{Cu}$ after eight passes of equal channel angular pressing (ECAP) ${ }^{[59]}$. Early studies on $\beta$ Ti alloys proposed that temperature could locally increase to above the austenite start temperature $\left(A_{S}\right)$, resulting in the reverse transformation ${ }^{[18,19,60]}$. Using a model by Pereira et al. ${ }^{[61]}$, we calculated the temperature rise to be $41{ }^{\circ} \mathrm{C}$ during high pressure torsion (HPT) of Ti-5553 under the experimental conditions that led to the reverse transformation ${ }^{[17]}$. This gave rise to a sample temperature of $\sim 66{ }^{\circ} \mathrm{C}$, much lower than $A_{S}$. In addition, $\alpha^{\prime \prime}$ plates were observed in the alloy even when it was deformed at $150{ }^{\circ} \mathrm{C}^{[62]}$. The assumption that local temperature rise could be responsible for the reverse transformation is thus dismissed. Instead, the Gibbs-Thomson effect was evoked to correlate the sizes of $\alpha^{\prime \prime}$ plates to Gibbs free energy, as shown in Figure $3^{[17]}$. The $\alpha^{\prime \prime}$ plates are cut constantly by severe shearing and their sizes can be reduced to as small as $10-20 \mathrm{~nm}^{[17,63]}$, leading to sharply increased energy of the system (Figure 3) and driving $\alpha$ " to transform back to $\beta$. This further facilitates grain refinement since nano-sized $\alpha$ " particles become $\beta$ grains of the same size during the reverse transformation ${ }^{[17,19]}$. In other words, the reverse transformation was driven by a high This article is protected by copyright. All rights reserved 
$\alpha " / \beta$ interfacial area, but in contrast to the conventional Gibbs-Thomson effect in which coarse particles grow at the expense of smaller ones, the extremely fine $\alpha$ " would be transformed by shearing rather than being dissolved, into the same-sized $\beta$ grains, keeping the nanocrystalline structure.

\section{Effects of strain rate on grain refinement}

As discussed earlier, grain refinement is a result of the competition between the rate of dislocation generation and absorption. Any factors which affect these two rates would influence the final grain size achievable. Two characteristic times can be considered in this regard, namely the time a dislocation takes to generate and travel across a grain until reaching a grain boundary $\left(t_{P}\right)$, and the relaxation time $\left(t_{r}\right)$ during which the dislocation is absorbed by the grain boundary through diffusion. When $t_{P}=t_{r}$, the minimum grain size at the steady state $\left(d_{S}\right)$ is obtained and can be related to strain rate $(\dot{\gamma})$ by ${ }^{[64]}$

$d_{S}=\left(\frac{D_{g b} \cdot b}{\dot{\gamma}}\right)^{\frac{1}{3}}$

where $D_{g b}$ is the grain boundary diffusion coefficient. A higher strain rate would result in a smaller minimum grain size since it shortens $t_{P}$ and leaves less time for dislocations to be absorbed at grain boundaries, leading to increased dislocation density and enhanced grain refinement.

Figure 4 presents the minimum grain sizes obtained by SPD at different strain rates in single-phase alloys and in the two Ti alloys involving SIMT. SPD of Ti-5553 at a high strain rate of $2 \mathrm{~s}^{-1}$, achieved by shear punching ${ }^{[20]}$, leads to much finer grains of $\sim 5-10 \mathrm{~nm}$, compared to $30-50$ $\mathrm{nm}$ obtained by HPT at $0.5 \mathrm{~s}^{-}$, and the grain sizes in other alloys are generally much coarser using 
strain rates $<0.5 \mathrm{~s}^{-1}$. In contrast to a wide range of strains investigated (Figure 1), the variation in strain rate is quite limited and the rates are generally very low (Figure 4). For example, among the few studies ${ }^{[39,52,65]}$ comparing strain rates, the range used is of the order of $0.01-0.1 \mathrm{~s}^{-1}$, not high enough to cause substantial changes in grain size. This is because it is difficult to achieve high strain rates in such widely used SPD processes as HPT and ECAP. In fact, most investigations do not even report strain rates despite their significant influence on dislocation dynamics (e.g. dislocation density, velocity and the rate of overcoming obstructions in the jerky glide regime ${ }^{[66]}$ ). Other than shear punching, dynamic plastic deformation (DPD) is a more recent SPD technique capable of producing high strain rates, and remarkably fine grains of $<70 \mathrm{~nm}$ have been obtained in pure $\mathrm{Cu}$ at $10^{3} \mathrm{~s}^{-1}$, although the grain refinement is a result of formation and fragmentation of nano-twins at high values of the Zener-Hollomon parameter rather than the effects on dislocation dynamics $^{[67]}$.

The effects of strain rate, however, need scrutiny in light of the observations in our shear punch testing (SPT) experiments in which a strain of 40 and strain rates of 0.02 to $200 \mathrm{~s}^{-1}$ were nominally applied on $\beta$ annealed Ti-5553 ${ }^{[20]}$. Shear localization during SPT generated one major shear band (SB) in the shear zone. A strain rate to $2 \mathrm{~s}^{-1}$ effectively refined the grain sizes inside the SB down to 5-10 nm, much finer than $30-50 \mathrm{~nm}$ obtained after HPT at a strain rate of $0.5 \mathrm{~s}^{-1}$ to an equivalent strain of $\sim 240$. Based on Equation 2, the ratio of the steady-state grain size for HPT to that for SPT is ${ }^{[20]}$

$\frac{d_{S(H P T)}}{d_{S(S P T)}}=\left(\frac{\dot{\gamma}_{S P T}}{\dot{\gamma}_{H P T}}\right)^{\frac{1}{3}}$

where $\dot{\gamma}_{S P T}$ and $\dot{\gamma}_{H P T}$ are the strain rates during SPT and HPT, respectively. Using the nominal strain rates of $\dot{\gamma}_{S P T}=2 \mathrm{~s}^{-1}$ and $\dot{\gamma}_{H P T}=0.5 \mathrm{~s}^{-}{ }^{1}$, the finest grain size obtained by HPT, $d_{S(H P T)}=30$ This article is protected by copyright. All rights reserved 
$\mathrm{nm}$, would correspond to $d_{S(S P T)}$ of $19 \mathrm{~nm}$, much coarser than the observed 5-10 $\mathrm{nm}$. This is because the actual strain rate inside the SB is much higher, estimated to reach as high as $250 \mathrm{~s}^{-1}$ at the applied (nominal) strain rate of $2 \mathrm{~s}^{-1}$, resulting in $d_{S(S P T)}$ of $4 \mathrm{~nm}$. This calculated grain size range of 4-19 $\mathrm{nm}$ is in good agreement with the experimental observations.

It should be pointed out that there is a limit to the application of Equation 3. At the maximum strain rate of $200 \mathrm{~s}^{-1}$ applied, much larger, elongated grains are observed. This is mainly attributed to the much shorter time available for dislocations to rearrange and produce high angle grain boundaries ${ }^{[20]}$. It is likely that there is an optimal strain rate in a particular alloy that favours dislocation generation over absorption at grain boundaries, leading to more effective grain refinement.

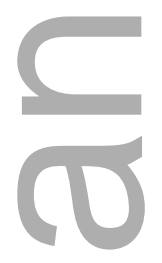

\section{Formation of equiaxed $\alpha$ in severely deformed $\beta$ Ti alloys}

Aging $\beta$ Ti alloys in the $\alpha / \beta$ phase field leads to the precipitation of hcp- $\alpha$ in bcc- $\beta$. It is well established that the $\alpha / \beta$ interface obeys the Burgers orientation relationship (BOR) of $\{0001\}_{\alpha} \|$ $\{110\}_{\beta}$ and $<11 \overline{2} 0>_{\alpha} \|<111>_{\beta}$. The BOR interface is semi-coherent with very low growth rate, leading to acicular $\alpha$ precipitates (Figure 5a). However, the morphology of $\alpha$ changes to equiaxed if the $\beta$ phase is severely deformed prior to aging (Figure 5b), although some plate-shaped $\alpha$ with semi-coherent interfaces may still be found (arrowed). This morphological transformation occurs if $\alpha$ can grow at a high rate in all the directions, accompanied by the disappearance of the BOR. It had been speculated that the precipitation of $\alpha$ at grain triple junctions would fulfil this condition ${ }^{[21,22]}$. A recent systematic study conducted by the authors ${ }^{[24]}$, however, shows the $\alpha / \beta$ interface during nucleation of $\alpha$ in a severely deformed Ti-5553 does initially obey BOR, but as illustrated in Figure $5 \mathrm{c}$ and $\mathrm{d}, \beta$ recrystallization and grain growth lead to the destruction of BOR and the replacement of 
the semi-coherent interfaces with incoherent ones. This allows the $\alpha$ nuclei, often formed at $\beta$ grain boundaries, to grow in all directions at equally high rates when the initial $\beta$ grains (i.e. before significant grain growth) are of the order of $10 \mathrm{~nm}$ attainable only by $\operatorname{SPD}^{[24]}$. This is consistent with the electron backscattered diffraction (EBSD) analysis on an equiaxed $\alpha / \beta$ structure which shows that $\alpha$ is bounded by mostly incoherent interfaces responsible for the formation of equiaxed $\alpha^{[68]}$. However, the growth of $\alpha$ becomes slower as aging continues so that it remains in the UFG range (i.e. $<1 \mu \mathrm{m})$ even after a long time. This can be attributed either to the pinning of the $\alpha / \beta$ interface by the $\beta$ grains (i.e. Zenner pinning ${ }^{[24]}$, or to the reduced interface mobility as a result of segregation of the $\beta$ stabilizing elements at the $\alpha / \beta$ interface ${ }^{[68]}$. Such a change in the morphology of

$\alpha$ gives rise to an ultrafine structure consisting of soft $\beta$ grains surrounded by a network of hard, equiaxed $\alpha$ grains. Although it is too early to conclude, there is indication that this microstructure improves ductility as deformation is transferred from the softer $\beta$ to the harder $\alpha^{[25]}$.

\section{Mechanical properties and potential biomedical applications}

Regardless of deformation mechanisms, grain refinement induced by SPD leads to grain boundary strengthening. Indeed, SPD has resulted in higher values of Vickers hardness (HV) and yield strength (YS) in different $\beta$ Ti alloys, as listed in Table 1, although ductility decreases as in other SPD processed alloys.

The elastic modulus (E) of $\beta$ Ti alloys is $\sim 30-80 \mathrm{GPa}^{[48,69,70]}$, much more compatible with < $30 \mathrm{GPa}$ for bone ${ }^{[71]}$ than $>100 \mathrm{GPa}$ for $\alpha$ - and $\alpha / \beta$ alloys currently used for orthopaedic implants, which makes them attractive for such biomedical applications, since a large difference in E would lead to bone resorption. Additionally, $\beta$ Ti alloys can be produced using none-toxic elements (e.g. those in Table 1), in contrast to Ti-6Al-4V, one of the most commonly used, which contains toxic elements of $\mathrm{V}$ and $\mathrm{Al}$. However, the low $\mathrm{E}$ is only obtainable in single $\beta$-phase Ti alloys with low strength. SPD processing is therefore desirable as it can greatly increase strength without affecting This article is protected by copyright. All rights reserved 
the low E. In fact, SPD can potentially be used to manipulate texture in order to reduce E even closer to that of bone. This is particularly achievable if a strong texture along a $\langle 100\rangle$ direction is produced $^{[47]}$, along which $\mathrm{E}$ is the smallest ${ }^{[72-74]}$.

In addition to mechanical and chemical biocompatibility of $\beta \mathrm{Ti}$ alloys, a recent study showed that SPD can be used for producing porous surfaces, which is crucial for protein adsorption and cell functions in orthopaedic implants. In particular, HPT was conducted on Ti-20Mo followed by aging at $550^{\circ} \mathrm{C}$ to produce a duplex, ultrafine $\alpha / \beta$ structure ${ }^{[75]}$. The equiaxed $\alpha$ particles produced were attacked more severely by etching, leading to a porous surface which enhanced cell growth and osteogenic capacity ${ }^{[75]}$.

Table 1 Mechanical properties of a number of $\beta$ Ti alloys processed by different SPD methods to various equivalent strains $\left(\varepsilon_{\mathrm{eq}}\right)$. $d$ denotes grain size $(\mathrm{nm})$, YS yield strength (MPa), HV Vickers hardness (MPa), El elongation (\%) and HE hydrostatic extrusion.

\begin{tabular}{|c|c|c|c|c|c|c|c|c|c|}
\hline \multirow[t]{2}{*}{ Alloy } & \multirow[t]{2}{*}{$\varepsilon_{\text {eq. }}$} & \multirow[t]{2}{*}{$d$} & \multicolumn{2}{|c|}{ YS } & \multicolumn{2}{|c|}{ HV } & \multicolumn{2}{|c|}{$E l$} & \multirow[t]{2}{*}{ Ref. } \\
\hline & & & $\begin{array}{l}\text { before } \\
\text { SPD }\end{array}$ & $\begin{array}{l}\text { after } \\
\text { SPD }\end{array}$ & $\begin{array}{l}\text { before } \\
\text { SPD }\end{array}$ & $\begin{array}{l}\text { after } \\
\text { SPD }\end{array}$ & $\begin{array}{l}\text { before } \\
\text { SPD }\end{array}$ & $\begin{array}{l}\text { after } \\
\text { SPD }\end{array}$ & \\
\hline $\mathrm{Ti}-45 \mathrm{Nb}$ & 3.5 & 300 & $\sim 450$ & $\sim 660$ & 150 & 188 & 24 & 20 & [46] \\
\hline $\mathrm{Ti}-45 \mathrm{Nb}$ & 15 & - & $\sim 450$ & 950 & 150 & 240 & 24 & 13 & [47] \\
\hline HPT & 170 & 90 & $\sim 450$ & $\sim 1000$ & 150 & 250 & 24 & 8 & [47] \\
\hline 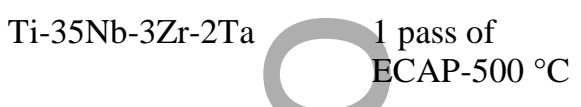 & $\sim 2$ & - & $\sim 409$ & 467 & $\begin{array}{l}193- \\
195\end{array}$ & $\begin{array}{l}203- \\
216\end{array}$ & 46 & 9 & [76] \\
\hline $\begin{array}{ll}\text { Ti-35Nb-3Zr-2Ta } & 4 \text { passes of } \\
& \text { ECAP-500 }{ }^{\circ} \mathrm{C}\end{array}$ & $\sim 8$ & 300 & $\sim 409$ & 390 & $\begin{array}{l}193- \\
195\end{array}$ & $\begin{array}{l}216- \\
224\end{array}$ & 46 & 16.5 & [76] \\
\hline $\mathrm{Ti}-29 \mathrm{Nb}-13 \mathrm{Ta}-4.6 \mathrm{Zr} \quad$ HPT & - & $\sim 45$ & 565 & $\sim 800$ & $\sim 210$ & $\begin{array}{l}250- \\
300\end{array}$ & $\sim 22$ & 7 & [49] \\
\hline Ti-24.6Nb-5Zr-3Sn ECAP & - & $<50$ & 445 & 920 & - & - & - & 5 & [77] \\
\hline $\begin{array}{l}\text { Ti-36Nb-2.2Ta-3.7Zr- HPT } \\
0.3 \mathrm{O}\end{array}$ & 15 & 50 & - & - & $\sim 260$ & 290 & - & - & [50] \\
\hline
\end{tabular}

\section{Conclusions}

This article is protected by copyright. All rights reserved 
(1) Significantly smaller grains of $<50 \mathrm{~nm}$ have been achieved by SPD in SIMT-involving metastable $\beta$ Ti alloys, compared to those in single-phase alloys (generally $>100 \mathrm{~nm}$ ). SIMT partitions the $\beta$ grains and the martensitic $\alpha^{\prime \prime}$ formed blocks dislocation movement, resulting in enhanced grain refinement. The $\alpha^{\prime \prime}$ phase undergoes reverse transformation into $\beta$ at large strains when its size becomes too small to be stable, leading to a nanocrystalline $\beta$ structure.

(2) An increase in strain rate to the order of $10-100 \mathrm{~s}^{-1}$ has produced further grain refinement to < $10 \mathrm{~nm}$, revealing the significant effects of strain rate on grain sizes.

(3) Equiaxed, rather than acicular, $\alpha$ precipitates would form between $\beta$ grains of $<\sim 10 \mathrm{~nm}$ upon ageing after SPD. Although the $\alpha$ nucleus obey BOR, subsequent $\beta$ grain growth would destroy the semi-coherent interface formed, causing it to grow into equiaxed shape.

(4) SPD can lead to effective strengthening without affecting the low elastic moduli in metastable $\beta$ Ti, making them desirable for orthopaedic implants.

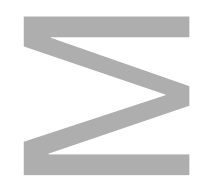

\section{Acknowledgement}

We are grateful to Ms. Mogeng Li for helping with the production of Figures 1 and 4. 


\section{References}

[1] R.Z. Valiev, Nat. Mater. 2004, 3, 511.

[2] R.Z. Valiev, R.K. Islamgaliev, I.V. Alexandrov, Prog. Mater. Sci. 2000, 45, 103.

[3] I.A. Ovid'ko, R.Z. Valiev, Y.T. Zhu, Prog. Mater. Sci. 2018, 94, 462.

[4] K.S. Kumar, H. Van Swygenhoven, S. Suresh, Acta Mater. 2003, 51, 5743.

[5] C.C. Koch, J. Mater. Sci. 2007, 42, 1403.

[6] H. Gleiter, Acta Mater. 2000, 48, 1.

[7] M.E. McHenry, M.A. Willard, D.E. Laughlin, Prog. Mater. Sci. 1999, 44, 291.

[8] Y.Q. Chang, Q. Guo, J. Zhang, L. Chen, Y. Long, F.R. Wan, Front. Mater. Sci. 2013, 7 , 143.

[9] S. Banerjee, P. Mukhopadhyay, Phase Transformations: Examples from Titanium and Zirconium Alloys, Pergamon Materials Series, Vol. 12, Elsevier, Oxford, 2007.

[10] A.A. Popov, I.Y. Pyshmintsev, S.L. Demakov, A.G. Illarionov, T.C. Lowe, A.V. Sergeyeva, R.Z. Valiev, Scr. Mater. 1997, 37, 1089.

[11] M. Wen, G. Liu, J.-f. Gu, W.-m. Guan, J. Lu, Appl. Surf. Sci. 2009, 255, 6097.

[12] D. Shin, I. Kim, J. Kim, Y.T. Zhu, Mater. Sci. Eng. A 2002, 334, 239.

[13] S. Zherebtsov, G. Salishchev, R. Galeyev, K. Maekawa, Mater. Trans. 2005, 46, 2020.

[14] R.S. Mishra, V.V. Stolyarov, C. Echer, R.Z. Valiev, A.K. Mukherjee, Mater. Sci. Eng. A 2001, 298, 44.

[15] G. Yapici, I. Karaman, Z.-P. Luo, Acta Mater. 2006, 54, 3755.

[16] T.W. Duerig, J.C. Williams, in Proc. Beta Titanium Alloys in the 80s (Eds.: R.R. Boyer, H.W. Rosenberg), Metallurgical Society of AIME, Atlanta, GA, US, 1984, 19.

[17] A. Zafari, X.S. Wei, W. Xu, K. Xia, Acta Mater. 2015, 97, 146.

[18] W. Xu, X. Wu, M. Calin, M. Stoica, J. Eckert, K. Xia, Scr. Mater. 2009, 60, 1012.

[19] W. Xu, K.B. Kim, J. Das, M. Calin, B. Rellinghaus, and J. Eckert, Appl. Phys. Lett. 2006, 89, 031906.

[20] A. Zafari, K. Xia, Acta Mater. 2018, 157, 174.

[21] T. Furuhara, T. Maki, T. Makino, J. Mater. Proc. Technol. 2001, 117, 318.

[22] T. Inaba, K. Ameyama, M. Tokizane, ISIJ Int. 1991, 31, 792.

[23] W. Xu, X. Wu, M. Stoica, M. Calin, U. Kühn, J. Eckert, K. Xia, Acta Mater. 2012, 60, 5067.

[24] A. Zafari, K. Xia, Scr. Mater. 2016, 124, 151.

[25] B. Jiang, S. Emura, K. Tsuchiya, Mater. Science Eng. 2018, 722, 129.

[26] A. Bhattacharjee, V.K. Varma, S.V. Kamat, A.K. Gogia, S.A. Bhargava, Metallu. Mater. Trans. A 2006, 37, 1423.

[27] C. Baker, Mater. Sci. J. 1971, 5, 92.

[28] H.Y. Kim, Y. Ikehara, J.I. Kim, H. Hosoda, S. Miyazaki, Acta Mater. 2006, 54, 2419.

[29] M. Marteleur, F. Sun, T. Gloriant, P. Vermaut, P. Jacques, F. Prima, Scr. Mater. 2012, 66, 749.

[30] C. Brozek, F. Sun, P. Vermaut, Y. Millet, A. Lenain, D. Embury, P.J. Jacques, F.C. Prima, Scr. Mater. 2016, 114, 60.

[31] J.Y. Zhang, J.S. Li, Z. Chen, Q.K. Meng, F. Sun, B.L. Shen, J. Alloys Compd. 2017, 699, 775.

[32] A. Vorhauer, W. Knabl, R. Pippan, in Proc. 2002 Nanomaterials by Severe Plastic Deformation - NANOSPD2 (Eds.: M. Zehetbauer, R.Z. Valiev), Wiley, Weinheim, Germany, 2004, 648.

[33] G. Rathmayr, R. Pippan, Acta Mater. 2011, 59, 7228.

[34] H.W. Zhang, X. Huang, R. Pippan, N. Hansen, Acta Mater. 2010, 58, 1698.

[35] K. Edalati, Z. Horita, Acta Mater. 2011, 59, 6831. 
[36] K. Edalati, T. Daio, M. Arita, S. Lee, Z. Horita, A. Togo, I. Tanaka, Acta Mater. 2014, 68, 207.

[37] Y. Iwahashi, Z. Horita, M. Nemoto, T.G. Langdon, Acta Mater. 1997, 45, 4733.

[38] Y. Iwahashi, Z. Horita, M. Nemoto, T.G. Langdon, Metall. Mater. Trans A 1998, 29, 2503.

[39] R. Pippan, F. Wetscher, M. Hafok, A. Vorhauer, I. Sabirov, Adv. Eng. Mater. 2006, 8, 1046.

[40] T. Hebesberger, H. Stüwe, A. Vorhauer, F. Wetscher, R. Pippan, Acta Mater. 2005, 53, 393.

[41] S. Descartes, C. Desrayaud, E. Rauch, Mater. Sci. Eng. A 2011, 528, 3666.

[42] M. Hafok, A. Vorhauer, J. Keckes, R. Pippan. Mater. Sci. Forum 2006, 503, 621.

[43] A. Zhilyaev, S. Lee, G. Nurislamova, R. Valiev, T. Langdon, Scr. Mater. 2001, 44, 2753.

[44] L. Kurmanaeva, Y. Ivanisenko, J. Markmann, C. Kübel, A. Chuvilin, S. Doyle, R. Valiev, H.-J. Fecht, Mater. Sci. Eng. A 2010, 527, 1776

[45] Z. Hegedüs, J. Gubicza, M. Kawasaki, N.Q. Chinh, Z. Fogarassy, T.G. Langdon, J. Alloys Compd. 2012, 536, S190.

[46] K. Ozaltin, W. Chrominski, M. Kulczyk, A. Panigrahi, J. Horky, M. Zehetbauer, M. Lewandowska, J. Mater. Sci. 2014, 49, 6930.

[47] A. Panigrahi, B. Sulkowski, T. Waitz, K. Ozaltin, W. Chrominski, A. Pukenas, J. Horky, M. Lewandowska, W. Skrotzki, M. Zehetbauer, J. Mech. behav. Biomed. Mater. 2016, 62, 93.

[48] Y.L. Hao, S.J. Li, S.Y. Sun, C.Y. Zheng, Q.M. Hu, R. Yang, Appl. Phys. Lett. 2005, 87, 091906.

[49] H. Yilmazer, M. Niinomi, M. Nakai, K. Cho, J. Hieda, Y. Todaka, T.H. Miyazaki, Mater. Sci. Eng. C 2013, 33, 2499.

[50] Y.B. Wang, Y.H. Zhao, Q. Lian, X.Z. Liao, R.Z. Valiev, S.P. Ringer, Y.T. Zhu, E.J. Lavernia, Scr. Mater. 2010, 63, 613.

[51] A. Zafari, X.S. Wei, W. Xu, K. Xia, IOP Conf. Ser.: Mater. Sci. Eng. A 2015, 89, 012055.

[52] A. Vorhauer, R. Pippan, Metallu. Mater. Trans. A 2008, 39, 417.

[53] T.H. Courtney, Mechanical Behavior of Materials, $2^{\text {nd }}$ ed. McGraw-Hill, New York, 1990.

[54] J. Mackenzie, Doctorial Thesis, University of Bristol 1949

[55] B. Azad, E. Borhani, J. Mater. Eng. Perform. 2015, 24, 4789.

[56] J. García-Infanta, S. Swaminathan, C. Cepeda-Jiménez, T. McNelley, O.A. Ruano, F. Carreño, J. Alloys Compd. 2009, 478, 139.

[57] E. Borhani, H. Jafarian, D. Terada, H. Adachi, N. Tsuji, Mater. Trans. 2012, 53, 72.

[58] M. Hong, K. Hono, W. Reynolds, T. Tarui, Metall. Mater. Trans. A 1999, 30, 717.

[59] M. Murayama, Z. Horita, K. Hono, Acta Mater. 2001, 49, 21

[60] W. Chen, Q. Sun, L. Xiao, J. Sun, Metall. Mater. Trans. A 2012, 43, 316.

[61] P.H. R. Pereira, R.B. Figueiredo, Y. Huang, P.R. Cetlin, T.G. Langdon, Mater. Sci. Eng. A 2014, 593, 185.

[62] A. Zafari, Y. Ding, J. Cui, K. Xia, Metall. Mater. Trans. A 2016, 47, 3633.

[63] A. Zafari, K. Xia, Mater. Sci. Eng. A 2018, 724, 75.

[64] O. Bouaziz, Y. Estrin, Y. Brechet, J. Embury, Scr. Mater. 2010, 63, 477.

[65] P.B. Berbon, M. Furukawa, Z. Horita, M. Nemoto, T.G. Langdon, Metall. Mater. Trans. A 1999, 30, 1989.

[66] U. Messerschmidt, Dislocation Dynamics During Plastic Deformation, Springer, Berlin, 2010.

[67] Y. Li, Y. Zhang, N. Tao, K. Lu, Acta Mater. 2009, 57, 761.

[68] B. Jiang, S. Emura, K. Tsuchiya, J. Alloys Compd. 2018, 738, 283.

[69] M. Niinomi, Materials Sci. Eng. A 1998, 243, 231.

[70] P. Majumdar, S.B. Singh, M.P. Chakraborty, Materials Sci. Eng. A 2008, 489, 419.

[71] J.-Y. Rho, L. Kuhn Spearing, P. Zioupos, Med. Eng. Phys. 1998, $20,92$.

[72] T. Inamura, H. Hosoda, K. Wakashima, S. Miyazaki, Mater Trans. 2005, 46, 1597.

[73] S.H. Lee, M.Todai, M. Tane, K.Hagihara, H.Nakajima, T.Nakano, J. Mech. Behav. Biomed. Mater. 2012, 14, 48.

This article is protected by copyright. All rights reserved 
[74] R. Karre, M. Niranjan, S.R. Dey, Mater. Sci. Eng. C 2015, 50, 52.

[75] N. Gui, W. Xu, J. Tian, G. Rosengarten, M. Brandt, M. Qian, J. Appl. Phys. 2018, 123, 095306.

[76] Z. Lin, L. Wang, X. Xue, W. Lu, J. Qin, D. Zhang, Mater. Sci. Eng. C 2013, 33, 4551.

[77] W. Xu, R. Figueiredo, X. Wu, S. Pauly, M. Stoica, J. Eckert, T. Langdon, K. Xia, Adv. Eng. Mater. 2011, 13, 1108.

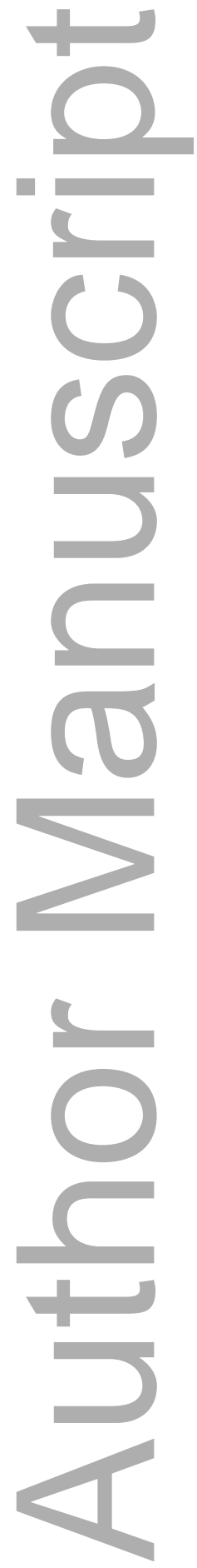

This article is protected by copyright. All rights reserved 


\section{Figure Captions}
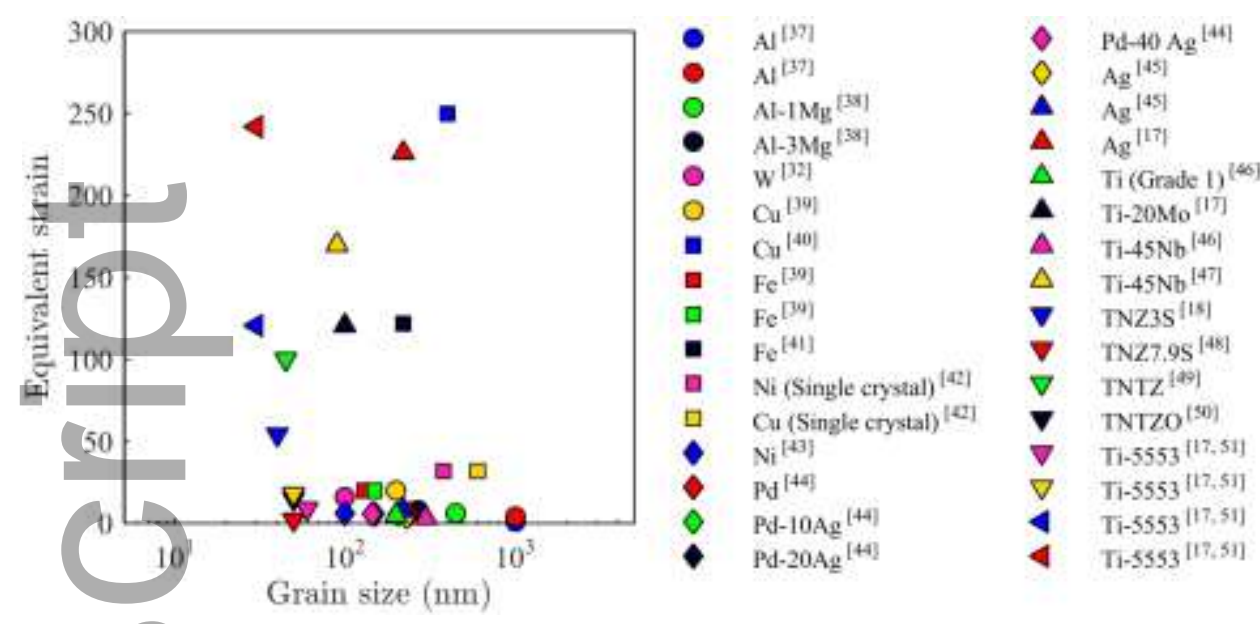

Figure 1. Grain sizes (measured by TEM or EBSD) in pure metals and single-phase alloys, as well as in Ti-5553, TNZ3S, TNZ7.9S, TNTZ, and TNTZO experiencing SIMT, after SPD to different equivalent strains. The finest grains of $<50 \mathrm{~nm}$ are achieved in the Ti alloys involving SIMT compared to $>100 \mathrm{~nm}$ in the other alloys.

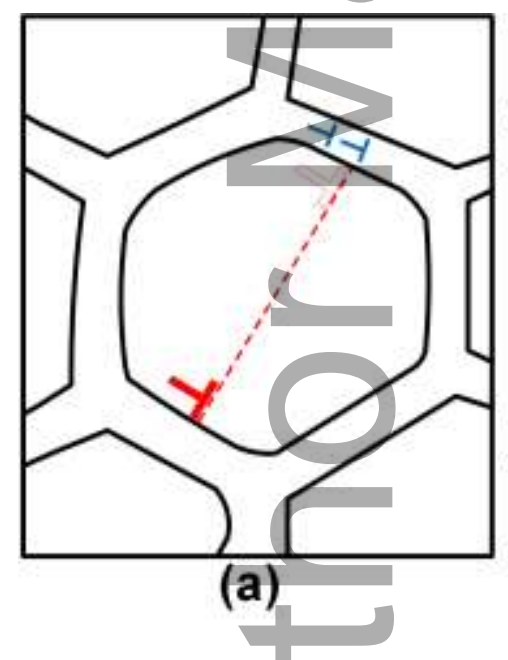

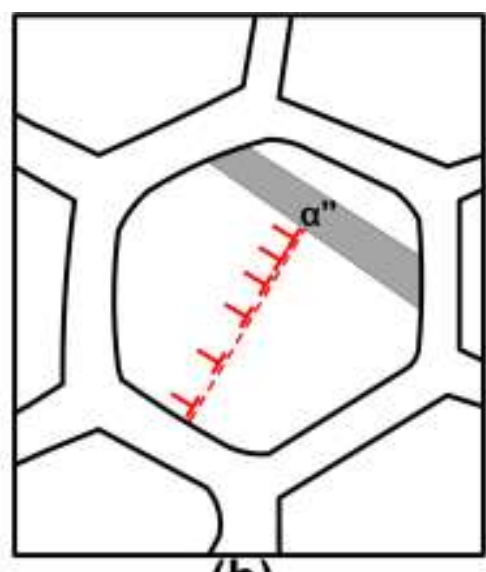

(b)

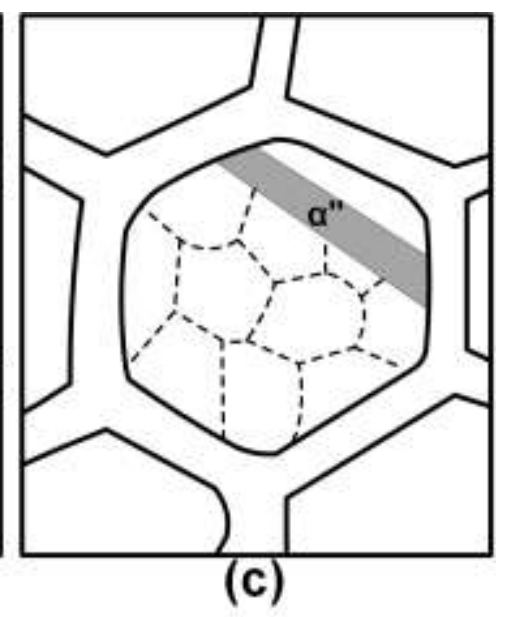

(c)

Figure 2. (a) Generation of a dislocation at a grain boundary (solid red) that crosses the grain to reach the opposite boundary (hollow red) where it decomposes into two dislocations (blue) absorbed by the boundary; (b) a pileup of dislocations at an $\alpha^{\prime \prime}$ plate, preventing their absorption and increasing their density, leading to (c) the formation of finer (sub)grains (dashed-lines).

This article is protected by copyright. All rights reserved 


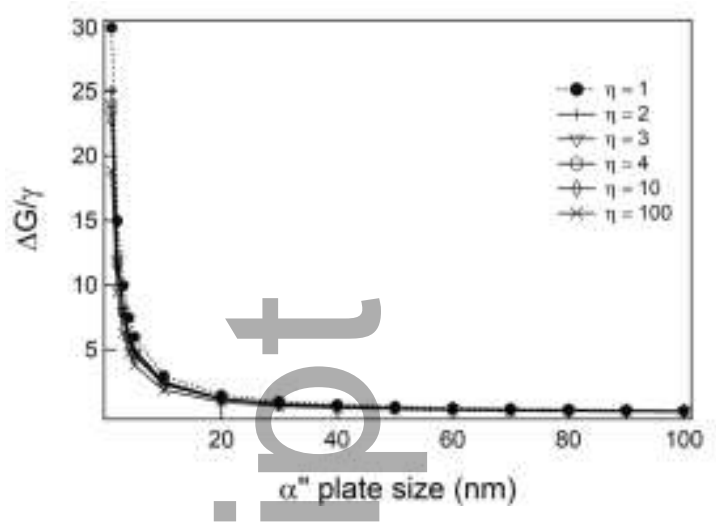

Figure 3. Gibbs free energy normalized by the $\alpha^{\prime \prime} / \beta$ interfacial energy $(\Delta \mathrm{G} / \gamma)$ as a function of the sizes of $\alpha$ " plates with different aspect ratios $(\eta) .{ }^{[17]}$
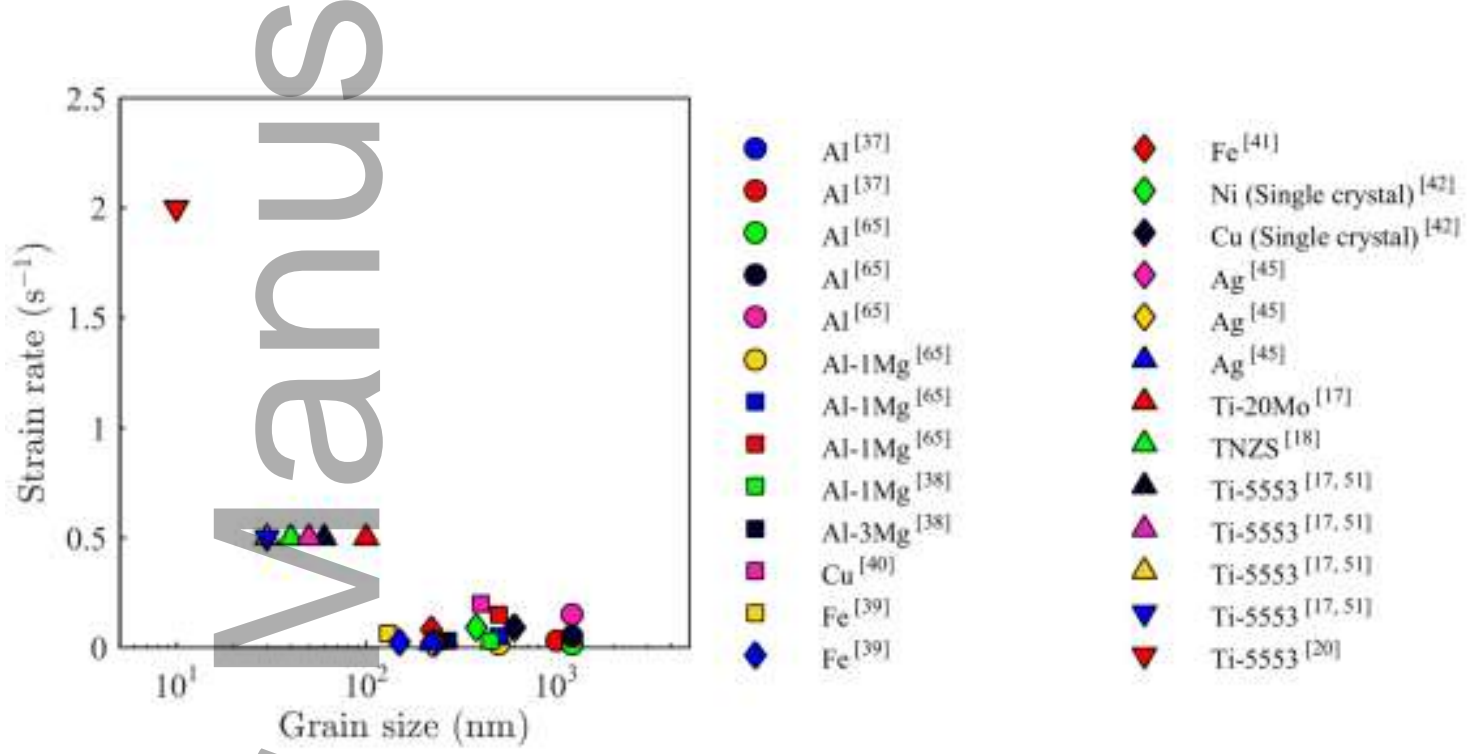

Figure 4. Grain sizes achieved in different single-phase alloys and those undergoing SIMT (i.e. TNZS and Ti-5553) after SPD at different strain rates.

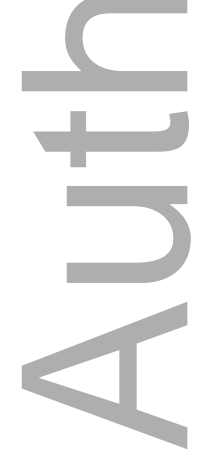

This article is protected by copyright. All rights reserved 


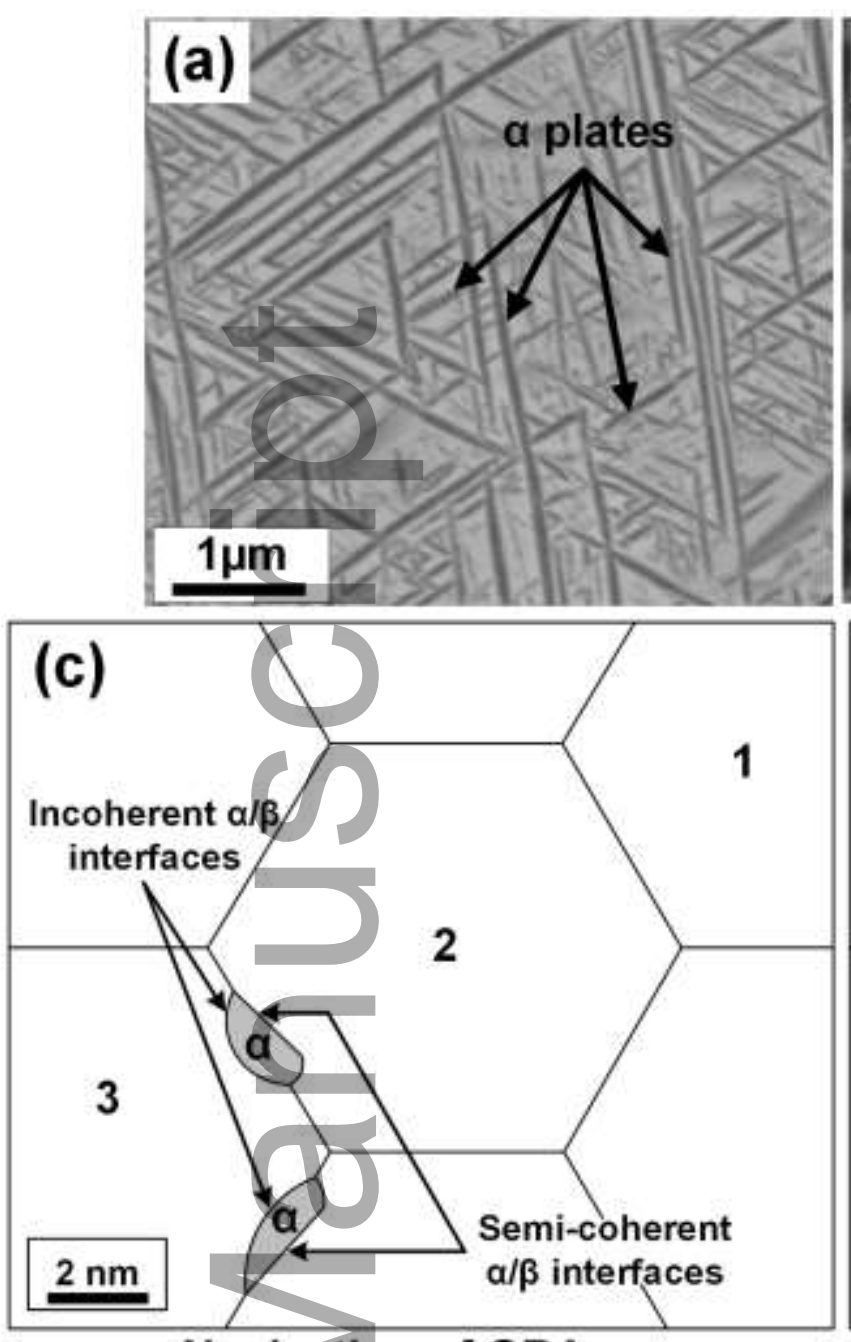

Nucleation of GBA
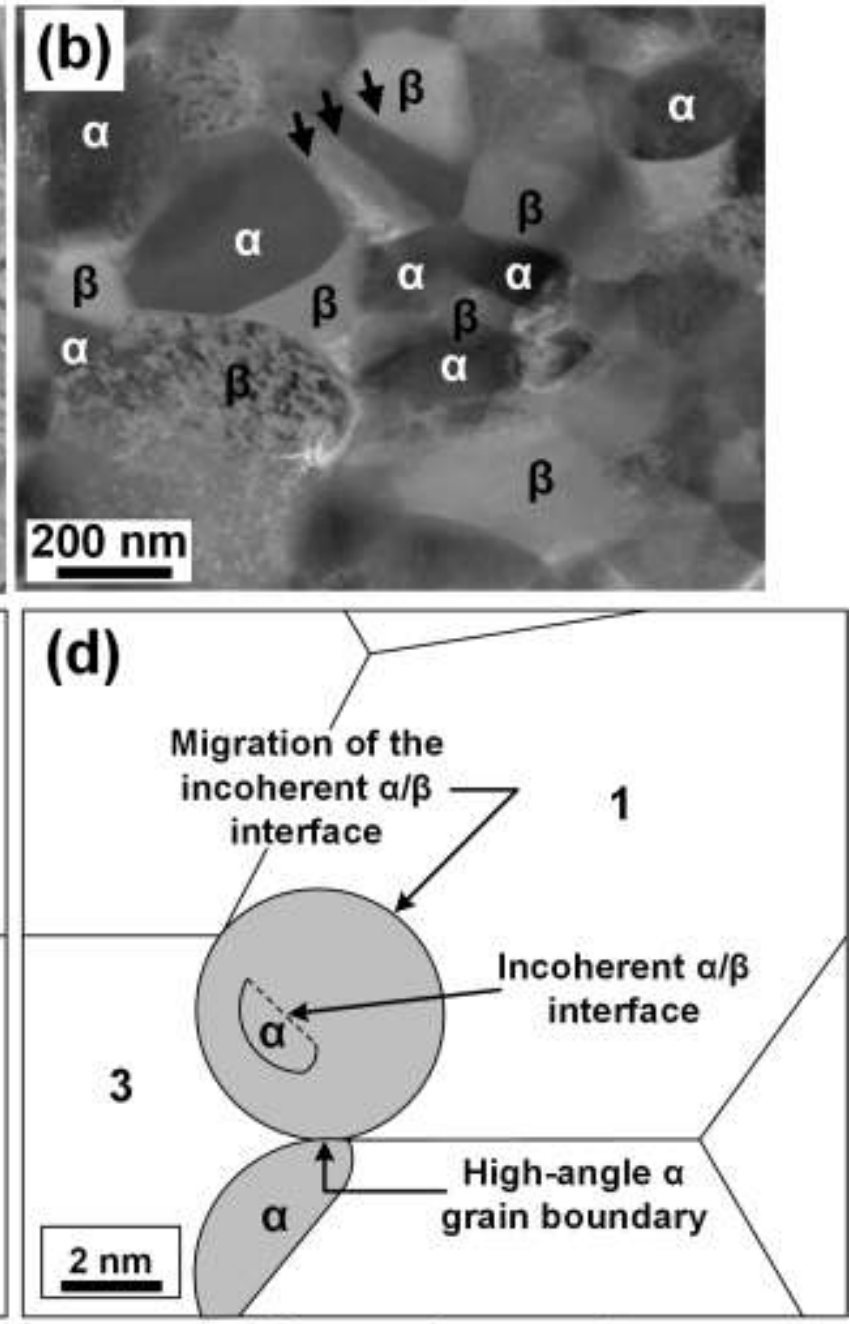

After grain growth

Figure 5. (a) Acicular $\alpha$ precipitated after aging at $600{ }^{\circ} \mathrm{C}$ for 1 hour in a $\beta$ annealed Ti-5553 alloy; (b) equiaxed $\alpha / \beta$ structure formed after aging at $600{ }^{\circ} \mathrm{C}$ for $1 \mathrm{~h}$ in an HPT processed Ti-5553 showing mostly incoherent but a small number of semi-coherent (arrowed) $\alpha / \beta$ interfaces; illustrations showing (c) nucleation of $\alpha$ at $\beta$ grain bounda BOR with one of the grains and forming incoherent interface with the other, and (d) replacement of the initially semi-coherent interface with an incoherent one (dashed line) after growth of grain 1 at the expense of grain 2, leading to the rapid migration of the newly formed incoherent interface and formation of equiaxed $\alpha^{[24]}$. 
The progress and fundamentals in severe plastic deformation (SPD) of metastable $\beta$ Ti alloys are overviewed, focusing on the role played by stress-induced martensitic transformation in grain refinement, the $\alpha$ " to $\beta$ reverse transformation triggered by SPD, the effects of strain rates, and the influence of SPD on $\alpha$ precipitation.
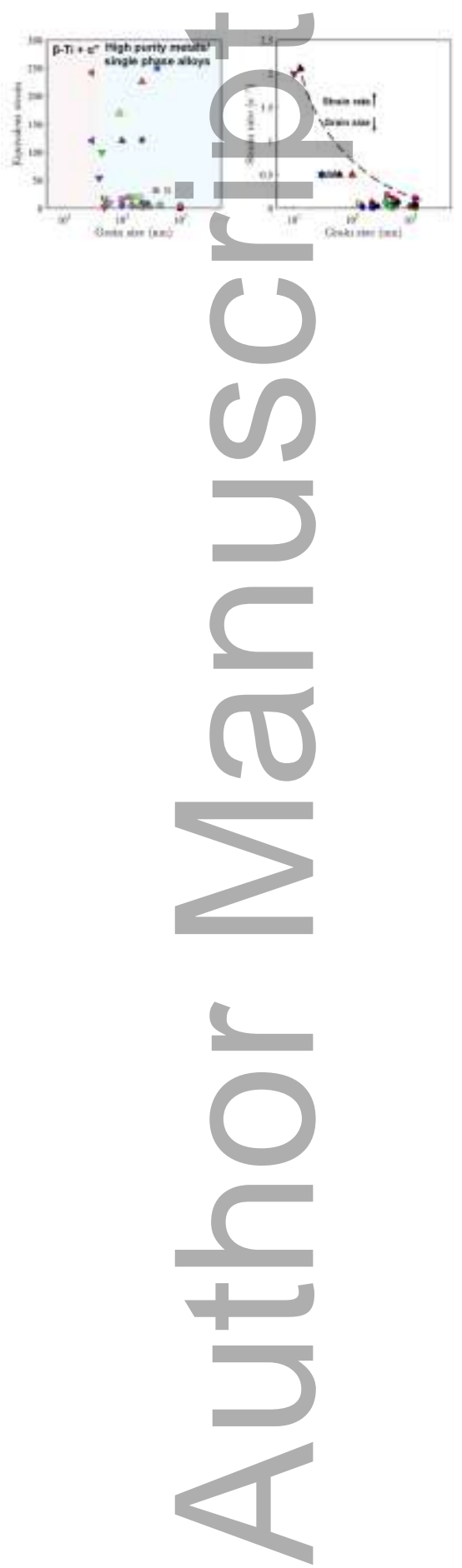

This article is protected by copyright. All rights reserved 


\section{Author Biography}

\section{Dr. Ahmad Zafari}

Dr. Ahmad Zafari received his PhD from the University of Melbourne in 2016, investigating phase transformation and grain refinement in severely deformed beta Ti alloys. He obtained B. S. from the Chamran University of Ahvaz in 2008 and M. S. from the University of Tehran in 2010. Dr. Zafari has been a Research Fellow in the Department of Mechanical Engineering at the University of Melbourne since 2017. His research is currently focused on microstructurs and mechanical properties in metallic materials, in particular titanium, produced by selective laser melting.
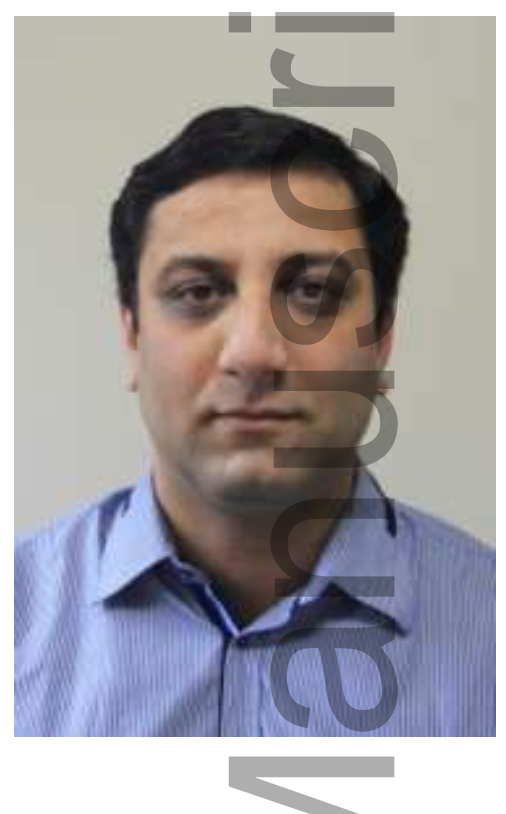

\section{Prof. Kenong Xia}

Prof. Kenong Xia received his PhD from University of Southern California in 1988, after B.E. (1982) and M.E. (1984) from Northeastern University in China. He joined Comalco Research Centre as research scientist in 1988 before starting his academic career at the University of Melbourne in 1993. He is currently Professor of Materials in the Department of Mechanical Engineering at the University of Melbourne.

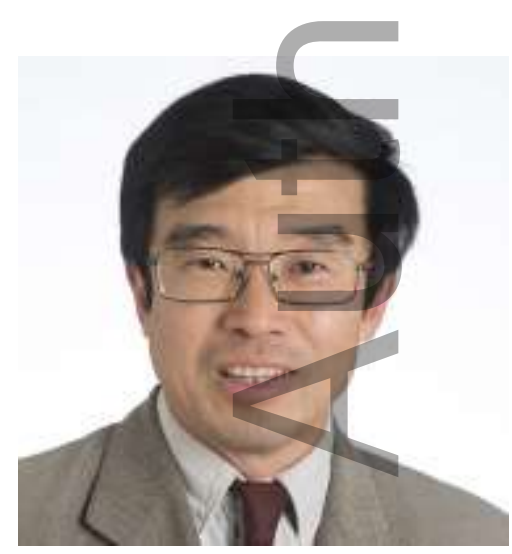

This article is protected by copyright. All rights reserved 


\section{University Library}

\section{- M M I N E R VA A gateway to Melbourne's research publications}

Minerva Access is the Institutional Repository of The University of Melbourne

Author/s:

Zafari, A;Xia, K

Title:

Progress in Severe Plastic Deformation of Metastable Beta Ti Alloys

Date:

2020-01

Citation:

Zafari, A. \& Xia, K. (2020). Progress in Severe Plastic Deformation of Metastable Beta Ti Alloys. Advanced Engineering Materials, 22 (1), https://doi.org/10.1002/adem.201900471.

Persistent Link:

http://hdl.handle.net/11343/286291 